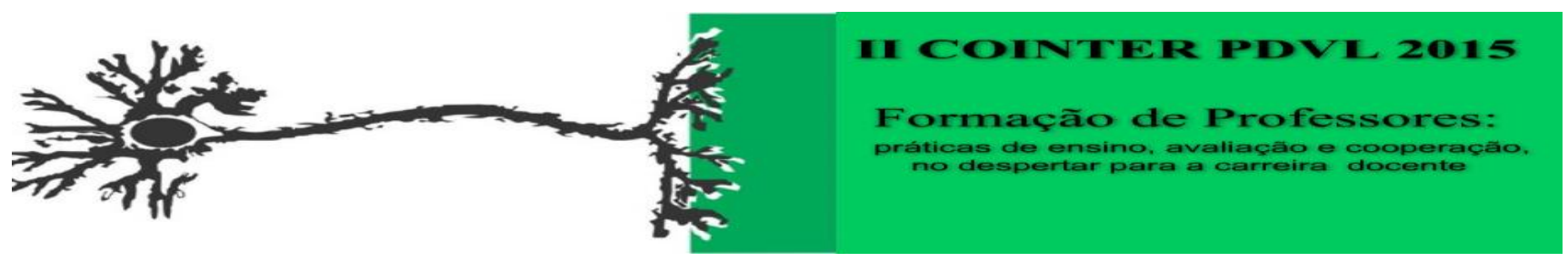

\title{
APRENDIZAGEM LÚDICA NO ENSINO DE GEOGRAFIA: CONTRIBUIÇÕES DE UM PROJETO DE EXTENSÃO
}

\author{
Apresentação: Comunicação Oral
Denis Rocha Calazans ${ }^{1}$; Júlio Gabriel Moreira da Silva ${ }^{2}$; Bárbara Cristynny Bispo de Almeida $^{3}$; Jacqueline Praxedes de Almeida ${ }^{4}$

\begin{abstract}
Resumo - Ensinar Geografia de forma significativa é um desafio para os professores do século XXI. Esse componente curricular passou por mudanças conceituais e metodológicas que transformaram uma disciplina mnemônica em uma ciência dinâmica. Mas o maior desafio dessa nova Geografia Escolar é a formação dos professores para trabalhar a disciplina dentro de uma concepção dinâmica e significativa para o aluno. Os cursos de formação de professores não instrumentalizam os docentes na sua formação inicial para atender as novas exigências do mercado de trabalho, o que leva o professor a buscar subsídios em sua formação continuada ou o aprendizado em serviço. Nesse contexto, surgiu um projeto de extensão, junto ao Instituto Federal de Alagoas, para desenvolver atividades lúdicas em escolas públicas, visando tornar o ensino de Geografia mais atrativo e contribuir com a melhoria da prática pedagógica dos professores da educação básica, contribuindo com seu aprendizado em serviço. O trabalho foi desenvolvido em uma turma do $5^{\circ}$ ano da Escola Municipal Professora Maria Cecília Pontes Carnaúba, que atende alunos carentes do bairro Antares da cidade de Maceió. O desenvolvimento do trabalho contou com o auxilio de dois bolsistas, que foram preparados para desenvolver atividades lúdicas com os alunos, norteadas pelo tema "consumo, consumismo e meio ambiente". Essa ação foi realizada na escola ao longo de cinco meses e contou com o apoio e a participação permanente da professora regente. Os alunos foram estimulados a construir em sala de aula materiais para serem usados nos jogos; houve o incentivo ao trabalho em grupo e a investigação de problemas apresentados em sala pelos bolsistas. Com o intuito de mensurar as contribuições que o projeto de extensão teria em relação ao público alvo, foi aplicado um questionário com os alunos, antes e após o desenvolvimento das atividades. O objetivo foi saber quais os conhecimentos que os alunos tinham em relação ao tema norteador e qual a percepção deles em relação às aulas de Geografia. Com a professora regente foi aplicado um questionário ao final das atividades para coletar as suas impressões sobre as possíveis mudanças que o projeto poderia ter provocado em seus alunos e em seu fazer pedagógico. Os resultados mostraram que os alunos se tornaram mais presentes nas aulas, diminuindo a evasão escolar, e mais participativos e interessados em aprender novos conhecimentos. A professora regente demonstrou interesse em dar continuidade às atividades lúdicas como ferramenta de ensino, bem como, repensar sua prática docente.
\end{abstract}

Palavras-Chave: Ensino de Geografia, Atividades lúdicas, Pedagogia de projetos, Consumismo, Meio ambiente.

\footnotetext{
${ }^{1}$ Professor Mestre do Instituto Federal de Alagoas (IFAL), Campus Maceió (AL), denisrc1 @ yahoo.com.br

${ }^{2}$ Aluno do Curso de Edificações do Instituto Federal de Alagoas (IFAL), Campus Maceió (AL), moreira_julio96@yahoo.com

${ }^{3}$ Aluna do Curso de Edificações do Instituto Federal de Alagoas (IFAL), Campus Maceió (AL), cristynny@ hotmail.com

${ }^{4}$ Professora Doutora da Universidade Federal de Alagoas (UFAL), Campus Maceió (AL), jpa_ufal@yahoo.com.br
} 


\section{Introdução}

O ensino da Geografia Escolar no Brasil é caracterizado por um processo mnemônico e dissociado da realidade do aluno. Priorizando estudos descritivos das paisagens e a memorização de dados estatísticos. Esse procedimento, enquadrado na corrente do pensamento geográfico tradicional e clássico prioriza a descrição e a memorização sem existir uma preocupação em levar o aluno a entender o que esta sendo estudado. Os Parâmetros Curriculares Nacionais (PCNs) nos alertam para essa prática quando afirmam que

No ensino, essa Geografia se traduziu (e muitas vezes ainda se traduz) pelo estudo descritivo das paisagens naturais e humanizadas, de forma dissociada dos sentimentos dos homens pelo espaço. [...]. Os alunos eram orientados a descrever, relacionar os fatos naturais e sociais, fazer analogias entre eles e elaborar suas generalizações ou sínteses. Explicá-las sim, porém evitando qualquer forma de compreensão ou subjetividade que confundisse o observador com o objeto de análise. Pretendia-se ensinar uma Geografia neutra. (BRASIL, 1998, p. 21).

As últimas décadas foram marcadas por mudanças no âmbito mundial e nacional em torno do objeto e método da Geografia como ciência, esses, por sua vez, tiveram repercussões diversas no ensino e serviram de estímulo para a inovação e a produção de novos modelos didáticos. (BRASIL, 2000). Surge então uma nova concepção de Geografia, não mais voltada para a memorização e a alienação do aluno, e sim uma ciência dinâmica, capaz de despertar a curiosidade do aluno, estimulá-lo a refletir sobre seu cotidiano e agir sobre sua realidade, tendo a percepção clara das interfaces entre o local e o global. Portanto, o professor de Geografia deve também perceber a necessidade de renovação das práticas utilizadas no ensino da Geografia escolar da Educação Básica. As aulas de Geografia também devem buscar o aprendizado significativo e lúdico, principalmente nos anos iniciais da Educação Básica, pois desse modo a disciplina tornar-se-á mais atrativa e voltada para a realidade dos discentes, dando-lhe significado.

Tornar um componente curricular atrativo ao aluno é uma das tarefas do professor, mas isso nem sempre é um procedimento que se aprende na sua formação inicial. Grande parte dos professores ainda é formada sem uma preocupação com a prática de ensino, ou seja, há uma priorização dos conhecimentos técnicos em detrimento dos conhecimentos pedagógicos que subsidiariam a práxis docente (PICONEZ, 2008). Assim a formação continuada se apresenta como elemento fundamental para a qualificação docente e para a melhoria do ensino. No entanto, a melhoria do fazer pedagógico, muitas vezes, ocorre em serviço, ou seja, ao longo da prática em sala de aula, desvinculada de um processo formal de qualificação que capacite o docente para enfrentar problemas do cotidiano e melhore sua práxis. 
A inserção de atividades lúdicas no ensino de Geografia se caracteriza como uma metodologia que auxilia no processo de ensino-aprendizagem e contribui para a melhoria da prática docente e para o maior envolvimento dos alunos. Souza e Yokoo $(2013$, p. 1) salientam

a importância da inclusão de jogos como parte integrante do processo de aprendizado para o ensino de Geografia. Por meio da inclusão de novos conceitos e conteúdos tornando assim mais dinâmica as atividades que abarquem o processo de ensino dos conceitos geográficos, contribuindo para a motivação dos alunos.

Nesse contexto, o desenvolvimento desse trabalho buscou contribuir com a formação continuada de professores da Educação Básica através da execução de atividades lúdicas, incentivando a mudança do fazer pedagógico e estimulando o uso de novas metodologias educacionais para tornar as aulas de Geografia mais atrativas, dinâmicas e significativas.

O desenvolvimento desse trabalho visou contribuir com o processo de aprendizado dos alunos do $5^{\circ}$ ano da Escola Municipal Professora Maria Cecília Pontes Carnaúba, através da aplicação de atividades lúdicas sobre o tema "consumo, consumismo e meio ambiente", visando mostrar o ensino de Geografia sob uma perspectiva dinâmica, atrativa e integrada à realidade do aluno. Ao mesmo tempo o trabalho buscou contribuir com a melhoria do fazer pedagógico dos professores de Geografia, promovendo o conhecimento de novas metodologias de ensino e o repensar de sua prática docente. $\mathrm{O}$ trabalho também buscou contribuir com a diminuição da evasão escolar, tornando o ambiente educacional mais atrativo, alegre e dinâmico.

\section{Fundamentação Teórica}

Trabalhar com temas motivadores na educação é uma técnica educativa que cria um fio condutor de ações que promove a interdisciplinaridade. Baseado nesse pressuposto foi escolhido para trabalhar nas aulas de Geografia o tema "consumo, consumismo e meio ambiente". Esse tema e a forma como as atividades foram executadas se encaixa na categoria de projeto, que segundo Moura e Barbosa (2006, p.12), são atividades

desenvolvidas por alunos em uma (ou mais) disciplina(s), no contexto escolar, sob a orientação do professor, e têm por objetivo a aprendizagem de conceitos e desenvolvimento de competências e habilidades específicas. Esses projetos são conduzidos de acordo com uma metodologia denominada Metodologia de Projetos, ou Pedagogia de Projetos. [...] os projetos de trabalho são executados pelos alunos sob a orientação do professor visando a aquisição de determinados conhecimentos, habilidades e valores. 
A pedagogia de projetos é uma forma de ensinar e também de aprender. Ela instiga os alunos a participar da construção do conhecimento e transformar os conteúdos em elementos significativos. Assim, o que muitas vezes é passado de forma pronta, mnemônica, se transforma em conteúdos dinâmicos. Essa mudança no fazer pedagógico é uma metodologia auxiliar no processo educativo, que possibilita ao docente repensar sua práxis, pois

a pedagogia de projetos surge como uma mudança de postura pedagógica fundamentada na concepção de que a aprendizagem ocorre a partir da resolução de situações didáticas significativas para o aluno, aproximando-o ao máximo do seu contexto social, através do desenvolvimento do senso crítico, da pesquisa e da resolução do problema. (ALVES; OLIVEIRA, 2008, p. 21).

Dessa forma, a escolha do tema visou alcançar os alunos em um período em que seus hábitos estão em formação e a aceitação de novas formas de agir e pensar é maior. Portanto, criar uma consciência de consumo ambientalmente sustentável através de atividades lúdicas e significativas atende as orientações dos PCNs. Além disso, o consumo é uma prática que tem por finalidade suprir as necessidades do ser humano. Quando esse consumo se torna exagerado passa a ser chamado de consumismo. Segundo Houaiss (2009), consumismo é o ato, efeito, fato ou prática de consumir em demasia, é o consumo ilimitado de bens duráveis, especialmente artigos supérfluos. Essa relação entre consumo e meio ambiente é predatória. Para consumir é preciso extrair, e a humanidade vem consumindo e extraindo em quantidades que, em alguns casos, ultrapassa a capacidade de suporte do meio (ALMEIDA, 2011). Assim, o ato de consumir se tornou algo extremamente prejudicial, tanto ao meio ambiente como também a pessoa que consome em demasia e a sociedade.

A Revolução Industrial provocou um grande aumento na produção, possibilitando o consumo a níveis nunca antes visto e a facilidade de atender as necessidades básicas de forma imediata gerou, de certa forma, o consumismo; mas o que deve preocupar ainda mais é que o consumo tende a aumentar com o crescimento da população mundial (Polon, 2011). Diante dessa realidade, é importante preparar as novas gerações para que os conhecimentos sobre as relações entre homem, sociedade e meio-ambiente permeiem seu aprendizado desde os anos iniciais da Educação Básica. Para isso, algumas disciplinas escolares como a Geografia apresentam maior identificação com esses temas.

Portanto, trabalhar as questões ambientais nas aulas de Geografia nos anos iniciais da Educação Básica é uma forma de educar os alunos para terem um consumo consciente. Nesse contexto está inserida a busca por uma aprendizagem significativa e uma nova forma de pensar o ensino de Geografia. 


\section{Metodologia}

A investigação adotou uma metodologia qualitativa, por essa, segundo Martins (2004, p. 292), ter por essência exigir daquele que a adota o "[...] desenvolvimento de uma capacidade criadora e intuitiva", possibilitando, por parte do pesquisador, a apreensão e compreensão da realidade que o cerca e a busca de soluções para os problemas encontrados.

Para a recolha de dados foi utilizado o questionário, elaborado com questões fechadas, para coletar dados dos alunos, e abertas, para coletar informações com a professora regente, de acordo com as orientações de Moreira e Caleffe (2006). Essa opção se mostrou mais adequada ao público pesquisado, já que as perguntas foram elaboradas para atender o nível de leitura e compreensão dos alunos do $5^{\circ}$ ano da Educação Básica. Já as questões abertas usadas com a professora regente visou coletar as impressões que o projeto causou na docente. A análise dos dados utilizou o paradigma interpretativo. Esse método de análise de conteúdo é uma ferramenta importante na compreensão da construção do significado que o ator social exterioriza no discurso, possibilitando ao pesquisador o entendimento das representações que o indivíduo apresenta em relação a sua realidade e a interpretação que faz dos significados a sua volta (SILVA; GOBBI; SIMÃO, 2005). Desse modo, o paradigma interpretativo proporciona um procedimento mais intuitivo, mais maleável e mais adaptável (BELL, 1997), permitindo, dessa forma, compreender como os inquiridos interpretam o ambiente onde atuam e como influenciam o ambiente (ALENCAR, 2002 apud SILVA; GOBBI; SIMÃO, 2005).

O desenvolvimento da atividade adotou um procedimento participativo, devido, principalmente, à natureza da proposta de intervenção direta. O procedimento constou de várias etapas. Primeiro, houve estudo do tema "consumo, consumismo e meio ambiente" com os bolsistas; depois houve a escolha das atividades lúdicas que seriam desenvolvidas na escola. Em um segundo momento, foi escolhida a Escola Municipal Professora Maria Cecília Pontes Carnaúba para se desenvolver as atividades. Essa escola atende alunos carentes do bairro Antares em Maceió e apresenta índices significativos de evasão escolar, principalmente nas turmas de $5^{\circ}$ ano do Ensino Fundamental. A proposta de trabalho foi apresentada a escola (Direção), a professora regente e aos alunos do $5^{\circ}$ ano.

Foram desenvolvidas três oficinas para elaboração de material para os jogos educativos, uma mostra de vídeos sobre meio ambiente e realização das atividades. A primeira atividade realizada foi o jogo da memória, que foi totalmente elaborado pelos alunos, associando imagens a seu significado. As imagens utilizadas estavam associadas a aspectos do tema motivador. A segunda foi a elaboração de conceitos. Essa atividade ocorreu a partir dos vídeos sobre meio 
ambiente. Durante a exibição dos vídeos os alunos identificaram palavras importantes do contexto e palavras desconhecidas, buscando seu significado e construindo conceitos no momento seguinte. Essa atividade foi realizada em conjunto, buscando a interação entre alunos, bolsistas, professora regente e o uso das tecnologias de comunicação e informação. A terceira atividade foi um jogo do “o que é o que é”. Nessa atividade os alunos escolheram palavras que representavam elementos significativos dentro do tema estudado e os bolsistas elaboraram charadas que os remetia a palavra. Os alunos foram divididos em grupos; o bolsista lia a charada e os grupos tentavam identificar a palavra correspondente. O objetivo dessa atividade foi reforçar o conhecimento sobre conceitos fundamentais de consumo, consumismo e meio ambiente.

Antes do início das atividades foi aplicado um questionário, visando investigar o nível de conhecimento dos alunos sobre o tema motivador (consumo, consumismo e meio ambiente) e as impressões que esses tinham sobre as aulas de Geografia. As percepções da professora regente foram coletadas com o uso de questionário fechado, objetivando descobrir quais contribuições do projeto foram significativas para sua práxis docente.

\section{Resultados e Discussão}

O desenvolvimento do projeto contou com a participação da Escola Municipal Professora Maria Cecília Pontes Carnaúba, que desde o primeiro contato se mostrou entusiasmada com a proposta. A professora regente foi muito receptiva ao trabalho e apresentou grande interesse e participação no desenvolvimento das atividades.

À medida que o projeto se desenvolvia a participação e o interesse dos alunos aumentou, havendo inclusive o pedido para a realização de mais atividades. Além disso, todos afirmaram que o processo de aprendizagem ficou mais "legal" e que o interesse pelas aulas de Geografia aumentou. O objetivo de tornar as aulas de Geografia mais atrativas, fugindo do aspecto mnemônico e descritivo fica evidenciado nas palavras de alguns alunos que destacam os aspectos positivos das atividades.

"Esse jogo foi muito bom, eu aprendi muito sobre consumismo e como economizar melhor. Eu gostei muito, foi um jeito de aprender brincando." (A 1)

"Legal bem divertido, da para aprender brincando. Nunca mais joguei e foi legal, é bom parar de estudar para brincar um pouco.” (A 2)

Uma das perguntas feita aos alunos foi se eles conversavam com os pais sobre consumo. Os resultados mostraram que após as atividades o índice de alunos que conversam com os pais sobre 
consumo aumentou em aproximadamente 30\%. Esse fato é bastante positivo, pois há uma troca salutar de informações entre pais e filhos, aumentando a participação dos alunos na organização dos gastos e o acesso dos pais a novos conhecimentos sobre orçamento doméstico. Informações essas adquiridas pelos alunos nas atividades desenvolvidas na escola.

Para coletar as informações sobre o entendimento que os alunos tinham sobre o que é ser consumista foi perguntado se eles se consideravam consumistas. No primeiro questionamento $31 \%$ declarou ser consumista. No questionamento após as atividades desenvolvidas em sala, o índice saltou para $67 \%$. Houve um aumento de $216 \%$, demonstrando que, tanto o entendimento sobre o que é ser consumista mudou, como também a percepção sobre seu modo de agir e de se perceber sofreu grande alteração. Os alunos também perceberam como a mídia influencia seus hábitos de consumo, pois $43 \%$ afirmaram que comprar por impulso provocado pela propaganda.

A percepção dos alunos sobre a relação consumo e meio ambiente também foi investigada, mostrando que a princípio $58 \%$ associava o consumo a potenciais impactos ambientais. Após as atividades esse índice subiu para $81 \%$, aumento de $40 \%$. Esse resultado mostra que houve uma maior conscientização sobre o processo produtivo e as relações entre produto, matéria prima e impactos ambientais.

A professora regente relata que, apesar das atividades serem desenvolvidas em apenas um dia da semana, às terças-feiras, a frequência dos alunos aumentou ao longo dos demais dias. Além disso, o índice de evasão, que segundo ela é próximo a 1/3 no segundo semestre, diminuiu. Ainda segundo a professora regente, a participação dos alunos nas demais aulas melhorou, "eles estão perguntando mais e trazendo muitas informações que antes não traziam”. Esse aspecto evidencia que o uso de aulas lúdicas pode contribuir com o processo de ensino-aprendizagem não só da Geografia, mas nas demais disciplinas, sendo uma metodologia que desperta o interesse do aluno e torna o conhecimento significativo.

O projeto também contribuiu para a melhoria do fazer pedagógico da docente, pois ela afirma que aprendeu muito e que irá incorporar algumas das atividades em suas aulas, expressando também o desejo de que o projeto continue no ano seguinte.

\section{Conclusões}

O ensino de Geografia tem muito a contribuir com a construção de uma educação cidadã, para isso é preciso se despojar de seu caráter tradicionalista descritivo e mnemônico para tornar-se uma Disciplina Escolar dinâmica e interessante para o aluno.

O uso da pedagogia de projetos é uma metodologia que auxilia o professor a dinamizar as 
aulas e criar o ambiente propicio para um aprendizado significativo, mas para isso ele precisa estar disposto a rever seus conceitos e seu fazer pedagógico.

As atividades lúdicas são ferramentas educativas que atraem o aluno para sala de aula e que tornam o aprendizado mais dinâmico e significativo. Portanto, cabe aos professores desenvolverem estratégias para inseri-las em seu fazer pedagógico de forma natural e contínua, não apenas como resultado de um projeto, mas como elemento constitutivo de sua práxis.

O projeto de extensão "consumo, consumismo e meio ambiente" atingiu seus objetivos, pois propiciou a transformação do fazer pedagógico da professora regente, provocou mudanças de hábitos nos alunos e plantou a semente de uma consciência ambiental voltada para o entendimento de que não se pode separar o homem da natureza e que todas as ações do ser humano têm reflexos no meio ambiente, no indivíduo e na sociedade.

\section{Referências}

ALMEIDA, J. P. de. Educação Ambiental: história e formação docente. Maceió: EDUFAL, 2011.

ALVES, M. C. S. de O.; OLIVEIRA, S. M. de. A (re) significação do aprender-e-ensinar: a pedagogia de projetos como uma proposta interdisciplinar no contexto da escola pública. Em Extensão, Uberlândia, v. 7, n. 2, p. 19-29, jul. 2008.

BELL, J. Como realizar um projeto de investigação. Lisboa: Gradiva, 1997.

BRASIL. Secretaria de Educação Fundamental. Parâmetros curriculares nacionais: geografia. Brasília: MEC/ SEF, 1998. 156 p.

BRASIL. Secretaria de Educação Média e Tecnológica. Parâmetros Curriculares Nacionais Ensino Médio. MEC, 2000.

HOUAISS, A. Dicionário Houaiss da Língua Portuguesa. Rio de Janeiro, Ed. Objetiva, 2009.

MARTINS, H. H. T. de S. Metodologia qualitativa de pesquisa. Revista Educação e Pesquisa, São Paulo, v. 30, n. 2, p. 289-300, maio/ago., 2004.

MOREIRA, H.; CALEFFE, L. G. Metodologia da pesquisa para o professor pesquisador. Rio de Janeiro: DP\&A, 2006.

MOURA, D. G.; BARBOSA, E. F. Trabalhando com Projetos: planejamento e gestão de projetos educacionais. Petrópolis: Editora Vozes, 2006.

PICONEZ, S. C. B. A prática de Ensino e o estágio supervisionado: a aproximação da realidade escolar e a prática da reflexão. In: FAZENDA, Ivani Catarina Arantes. et al. A prática de Ensino e o Estágio Supervisionando. 15 ed. Campinas: Papirus, 2008, p. 15-38. 
POLON, L. C. K. Sociedade de consumo ou o consumo da sociedade? um mundo confuso e confusamente percebido. In: $5^{\circ}$ SEMINÁRIO NACIONAL ESTADO E POLÍTICAS SOCIAIS, Anais... Cascavel, outubro de 2011.

SILVA, C. R.; GOBBI, B. C.; SIMÃO, A. A. O uso da análise de conteúdo como uma ferramenta para a Pesquisa qualitativa: descrição e aplicação do método. Revista Organizações Rurais Agroindústria, Lavras, v. 7, n. 1, p. 70-81, 2005.

SOUZA, I. F. de; YOKOO, S. C. Jogo lúdico no ensino de geografia. In: VIII ENCONTRO DE PRODUÇÃO CIENTÍFICA E TECNOLÓGICA, Anais... Campo Mourão, outubro 2013. 